\title{
Research on the Application of Flipped Classroom in College Physical Education
}

\author{
Di Han \\ Jilin Agricultural University, Changchun, Jilin, 130000
}

Keywords: Application, Flipped Classroom, College Physical Education

\begin{abstract}
It is considered to be a more effective teaching mode in the teaching of primary and secondary schools. At present, the application of the classroom in the teaching of higher vocational colleges is almost blank. This paper shows that the teaching mode of the classroom teaching in the higher vocational colleges the application in the teaching of physical education is feasible. Although there are some problems in the process of curriculum implementation, the specific teaching process needs to be improved constantly, but the introduction of the teaching mode can provide a more effective way for college students to learn.
\end{abstract}

\section{Introduction}

With the continuous application of information technology development, a wide range of physical education teaching model has become the main direction of modern physical education reform, in college classroom teaching, teachers began to gradually apply advanced science and technology to carry out the actual teaching. Especially in the flip classroom teaching mode, it is for the major institutions of the current reform and development of physical education provides a practical basis. The main teaching goal of the classroom is to cultivate students' emotional consciousness, innovative spirit and practical skills. Enable students to study the physical education curriculum in a relaxed state to promote a pleasant experience in a strong learning atmosphere, in order to promote students the overall development of physical and mental health in physical education.

\section{The Meaning of Flipped Classroom Teaching}

Flip classroom teaching is also called the reverse of the classroom, due to the practical application of a very good teaching effect, and by the teachers and students of the widely loved, and therefore dubbed the reputation of efficient classroom. The first class came from the University of Miami in the United States several teachers in the school, the application is the use of advanced multimedia resources to implement network video teaching equipment, teachers in the actual teaching is no longer take too much classroom time to impart knowledge content, but to fill these valuable information into the network equipment, requiring students to make full use of class spare time from the main learning, students can take podcasts, video lectures and video and reading in one form of Ipad to complete the classroom of learning. At the same time, flip the classroom for students to create an online discussion of the form, and in the course of learning for those who do not know how to timely access to the required information. In other words, the reform of classroom teaching can change the traditional teaching mode under the monotonous classroom atmosphere, for students to create a more colorful teaching form and content, is the new era of college physical education in a major change.

\section{The Application Features of Flipped Classroom in College Physical Education}

Give Full Play to the Main Form of Students. Under the traditional teaching mode, the teachers use the indoctrination method to teach the students. In this kind of teaching environment, the 
students can only passively accept the contents of the study, and continue to repeat the demonstration action mechanically, but it is not a good grasp of action essentials, can not be mastery. In the teaching mode of flip classroom, teachers can according to the ability of students to rationally change the role of the class returned to the students, emphasizing the student's dominant position. Before teaching, teachers can follow the overall situation of class students to design targeted guidance links, and actively play a guiding role, so that every student can be integrated into the teaching activities, in order to enhance the students participate in the initiative and initiative, and thus promote the students to self-study. For example, teachers in teaching a sports action, you can combine sports video or related information to teaching. At the same time, not only to let the students move up, the idea should also be active, you can arrange for students to communicate and show each other, and in this session to encourage students to guide students, reflecting the efficiency of physical education.

Innovative the Teaching Philosophy. The new period of college physical education teachers should actively change their traditional teaching philosophy, keep up with the pace of development of the times, will flip the classroom teaching mode to the actual teaching to adapt to the new situation of physical education, new changes, and in specific application to reflect the innovative teaching philosophy, highlight the optimistic and advanced teaching methods. At the same time, flip the classroom form can help simplify the teaching process, from the traditional linear teaching to multi-channel diversification of teaching, teaching materials in the design of the integration of more fresh teaching elements to keep up with the times, practice teaching to add more practical teaching content to promote the university sports teaching towards the direction of innovation and development forward.

Make Teaching Content More Systematic. Inverted classroom teaching model in the specific application can be achieved in the teaching content of the system, and to enable students from a single teaching model freed, so that students learn the content becomes more deep, diversified, and can effectively pre-study, classroom teaching and class review of the close combination of students to promote the efficiency of learning greatly enhanced. In the classroom part of the program, teachers can recruit some of the students associated with the teaching of video information, and students with the common to watch and explore, so that students have a certain understanding of the content, for the next teaching to pave the way of the class links, teachers can take group discussions, group competition and a series of forms to carry out teaching activities, in order to enhance the students' interest in learning, active classroom atmosphere. In the course of the post-class review, teachers can use the campus network platform to communicate with students and online questions and you can encourage students to record the way to guide the course of action, so that students can conduct an efficient review after school.

\section{The Importance of the Application of Flipped Classroom Model in College Physical Education}

The Embodiment of Personalized Teaching. Physical education is mainly around the action skills to carry out a process of teaching, action skills with the difficulties and key content, is the university sports teaching need to grasp the main line. As we all know, the traditional university physical education teaching process, usually rely on teachers' "voice" and "physical" to guide students, students by virtue of "ear" and "seeing" the way to accept sports knowledge and skills, which led to teachers on sports action focus and difficult to explain the content is not enough, the presentation of the action is not enough image and intuitive, resulting in students in the course of practice only know the action but I do not know the action, but the master of the action is not very strong grasp of the enthusiasm of the students was reduced, the enthusiasm of sports and skills learning is not high. In the classroom, teachers can prepare a micro video for students in advance, so that students through the video viewing, and then the action of the discussion and research, you can let the learning of sports knowledge to break the time and space constraints, to achieve the "everyone, everywhere, "all the learning objectives; micro-video viewing, when the students understand the action is not thorough enough, you can replay or pause, so you can take into account each student, to help students with poor ability to improve effectively. 
The main classroom is to advocate students with the school's network platform, proactively on the sports knowledge and skills to discuss, analyze and learn. In the physical classroom for a limited time to practice and skills to practice, so that teachers have enough time to correct and guide the mistakes of students, the students themselves exist in the classroom effectively solve the problem. Classroom teaching is more efficient, so that students can fully meet the requirements of the body exercise, so that students' self-confidence has been enhanced, and to achieve the purpose of cultivating students' team spirit.

Promote the Rapid Formation of Sports Skills. In combination with the simple tasks in the flip classroom, teachers can let the students do their own, and will watch the video after the use of online way to discuss Liu. For some of the more complex tasks, teachers can allow students to pre-class study of the contents of the appropriate self-study, through the form of independent inquiry for complex issues to learn, so that students can grasp the content of the more solid, if during the course of pre-class inquiry, students meet their own problems can not be solved, teachers can guide and explain in the classroom and through collaborative ways to solve, in this way more conducive to students to learn and maintain.

\section{The Specific Tactics of Applying Flipped Classroom Teaching in College PE Classroom Teaching}

Produce a Wealth of Network Video in the Pre-Class. In the classroom teaching mode, the teaching video is the most important teaching resource, and it is also the most important teaching form in the classroom teaching. Teachers in the specific application to be combined with the characteristics of teaching mode, combined with the actual teaching content, in the network resources to find the reference value of the first line of physical education teacher action video, and in the production of the best time to control in the $5 \sim 10 \mathrm{~min}$, in the design of the plate can be added to the introduction of some of the course action and explain the fragments, the relevant part of the teaching case and the well-known college students after learning and so on, so that students in the pre-class watch at the same time to enhance their learning interest and curiosity, the expected value of this lesson. At the same time, the choice of teaching video content should be tendencies, we should focus on taking into account the core purpose of physical education, fully combined with the actual situation of students, the appropriate grasp of the degree of difficulty, to design a reasonable form of guidance, and then make the students review effect is enhanced. For example, before learning a basketball course, teachers can combine the basketball technical requirements in detail, in the actual video design refinement of teaching content, according to the students in the usual teaching activities in the actual performance to design a clear video content, you can add Ball, passing, dribbling, three-step layup and dribbling and other related video content, so that different levels of students can be targeted to choose. In the design process, teachers should also focus on the points of interest to students, such as class boys love basketball this sport, usually in class under the total competition and teachers can video production in the final design of $2 \mathrm{~min}$ NBA video. Wonderful shooting clips and NBA star game promotion video, and finally hit the students please look forward to the upcoming open to the basketball learning tour of the rolling subtitles, announced the video playback is completed. Through this video content, you can fully attract the attention of students to enhance the students' interest in learning and students will also watch the content of basketball to have a general understanding of the content, thereby enhancing the effect of student preview.

Complete the Teaching Content based on the Teaching Characteristics of Flipped Classroom. In the actual physical education, teachers should be based on pre-class teaching design content to develop the corresponding teaching tasks, in the study for students to play the relevant actual case video, combined with the video content to the students to explain the sports system Knowledge and action skills essentials, and in the actual teaching practice for the students to create a variety of practice forms, into more teachers and students interactive game links, and then create a strong learning atmosphere, enhance the students' interest in learning to achieve the essential purpose of efficient teaching. For example, in the college physical education teaching exercises for 
the aerobics practice, because some of the skills of teachers is not up to standard, aerobics practical demonstration of the lack of beauty, seriously affect the students' practical learning effect. Teachers in order to guide the beauty of aerobics will be fully demonstrated, you need physical education teachers have better professional skills and their own body beauty, such a request itself will be in the actual teaching teachers to add a certain difficulty. Therefore, in response to this problem, the physical education teachers can fully combine the teaching characteristics of the flip classroom mode, find out a wealth of relevant teaching resources before class, in the actual classroom teaching to achieve multimedia technology teaching, which to a large extent the teaching effect. In the traditional teaching mode, teachers play music for students, students in addition to remember the action itself, but also keep up with the rhythm of music, so learn some complicated. In the teaching of the classroom, teachers can teach their students in the basic action, the students can play video, students can follow the picture content to practice together, in video teaching, if you do not understand the place, teachers can Slow down the playback speed, in order to facilitate the students to learn, enhance the students' learning fun, enhance the teaching effect.

Enhance the Show and Evaluation of Learning Results. After the end of the classroom learning content, teachers should actively lead students to review after school. In the traditional classroom teaching, teachers pay more attention to the teaching of class, students even in the course of learning to learn the tactics and skills will be forgotten in the long interval. This requires teachers to organize students in the school after school through the form of online network platform to share the learning results in a timely manner to encourage students to communicate more, learn more, teachers can class this class students, combined with the contents of the site to take a live report, or The team co-production PPT and a variety of micro-video and other network upload, and thus facilitate the timely acceptance of students learning results.

\section{Conclusion}

As a product of information technology development, it is a new transformation of PE teaching in the new period, and it has a profound impact on the future development of physical education. In the application of the classroom teaching mode, the PE teachers should fully and modernize the network resources to design a richer and more interesting teaching content so that students can learn efficiently in the campus network platform. To enhance students' awareness of autonomous learning and independent research ability, so that students can actively expand their existing knowledge reserves, so as to obtain spiritual and psychological satisfaction and constantly promote the university physical education curriculum is becoming more perfect.

\section{References}

[1] Zhuoji, Lu Chuntao.Application of flip classroom model in physical education teaching in higher vocational colleges [J]. Journal of Liuzhou Teachers College 2014 (06)

[2] Liu Hongcun, Dong Lunhong. Construction and exploration of the teaching model of leisure physical education curriculum based on flip classroom [J] .Journal of Changzhou University (Social Science Edition). 2014 (06)

[3] Shi Min. Information technology in the college sports elective course in the use and practice [J]. Journal of Xiangnan University. 2014 (05)

[4] Zhao Hui, Feng Hongxin.Experimental study on the application of flip classroom in the teaching of sports health course [J] .Progress in Sports. 2014 (05)

[5] Chen Xiaoan. SWOT analysis of the application of flip teaching model in sports human science curriculum [J]. Heilongjiang Science and Technology Information. 2014 (19)

[6] He Ke anti. From the "flip classroom" the essence of "flip classroom" in the future development of China[J] .Electronic Education Research. 2014 (07) 